\title{
DEPLOYMENT OF A GENERIC METHOD IN THE DESIGN OF DIGITAL LEARNING ENVIRONMENTS USING A COLLABORATIVE AUTHORING TOOL
}

\author{
Carlos Bohorquez ${ }^{1}$ and Pascal Marquet ${ }^{2}$ \\ ${ }^{I}$ My-Serious-Game - University of Strasbourg, France \\ ${ }^{2}$ University of Strasbourg, France
}

\begin{abstract}
This paper describes the first stages on the development of a design method of digital trainings using the collaborative authoring tool "ALO". Based on the theory of instrumental conflict (Marquet, 2005), this method highlights the necessity of the design digital trainings under the optimal harmonization for users/learners in didactic, pedagogical and technical terms. By the implementation of an artificial intelligence, we will collect the data acquired from users' experiences to analyse their performances. The result of this analysis will be given to the trainer/designer in order to improve future trainings by predictive learning models increasing cognitive skills and the measurement of the efficiency of a digital training.
\end{abstract}

\section{KEYWORDS}

Digital Trainings, Learning Analytics, Instrumental Conflict, Artificial Intelligence, xAPI

\section{INTRODUCTION}

For many of companies, the improvements on employee's expertise demands a financial investment. Some companies choose to adopt digital learning as a solution. They make a call for learning services organisations to guide them through this strategy (Loh, 2013). However, All, A \& al, (2015) points out the lack of evidence on the effectiveness of digital trainings for learning improvement.

This document describes the first stages of a generic method in the development of digital trainings using the collaborative authoring tool from My-Serious-Game, a French company specialized in the design of digital trainings. Marquet (2005) describes the instrumental conflict as a possibility of harmonizing the learner interface with valuable functionalities on the teaching topics. Based on this theory, our method contributes then to define the appropriate learning elements to a suitable scenario with the correct/adapted learner interface.

Our main objective is to obtain users' experience data through the implementation of an artificial intelligence allowing us to:

1. Apply the generic method through the implementation about cognitive activities (Instrumental Conflict Influence).

2. Collect user's performances data by the implementation of tracking supporting tools (xAPI, Learning Analytics).

3. The analyse the results of the users' performance will provide us a verification or not about our generic method. On this stage we will identify the main aspects generating an instrumental conflict.

4. With the data generated and the results of performances, we will define a new path of cognitive activities and the effectiveness of trainings in terms of learning outcomes.

First, we will detail the context in which this approach is based, following on the conceptual framework and methodology to identify the design aspects of training and the application of artificial intelligence. At the moment of the depot of our document, no results have been analysed yet. However, the matrix of Learning Analytics and path performances have been stablished to predict the first tendency of our method. 


\section{RESEARCH CONTEXT}

The last couple of decades, specifically after the inclusion of learning technologies among the academic institutions, educational engineering and digital learning design have been mobilized to identify the required improvement where technology contributes to learning processes (Linard, 2002; Henry, 2007; Baron, 2001). Paquet (2014) describes educational engineering as a method allowing models and charts organizing learning activities, the selection of the technological display with the teachers' role and resources, including digital environments.

According to the industry, the choice of the corresponding training to improve employees' skills is one of the main concerns for stakeholders (Loh, 2013). An optimal solution detected to hold back this concern comes with the hybridization of those trainings meaning the mix between digital and classroom learning environments (Peraya, 2010). This hybrid environment guides the learner through the adaptation for the use of technologies for learning improvement (Lebrun, 2006). This hybridization could also facilitate the role of the trainer/designer due to the analysis generated to the most stablished and relevant elements to perform during the training.

The evolution of the design process for those hybrid trainings develops more technological learning devices. According to our work, the authoring tool it's a trademark product of My-Serious-Game. A French company leader in the development of digital trainings. Supported by this authoring tool, designers/trainers will be guided to customize trainings with a large set of possibilities (plug-in). The use of artificial intelligence and the XAPI technology contributes with the identification of more details related to learners' performances.

This occurs during the training with the corresponding path and behaviour analysis (Bennane, 2012). The addition of A.I. (Artificial Intelligence) to this tool relies on the importance of the access to previously complex information about the learning process. The data obtained from those performances would be modified allowing trainers to analyse the elements that contribute or deteriorate the learning process (Cleveland, M., Olimpo, J, DeChenne-Peters, S. 2018).

The measurement about those trainings in terms of efficiency and improvement on cognitive skills will be hold by the design of an architecture with the interpretation and predictions of the training design assessment with an exploratory analysis (Mirroahi \& al., 2016).

\section{THEORETICAL FRAMEWORK}

Humans through history have always been elaborated tools to help them resolve some particular issues (Leroi-Gourhan, 1967). Those tools have been designed under the anthropological concept of "artefact" for their attachment to a social structure. Artefacts then become "instruments" as soon as they contribute with a practical solution to a problem, applied to a concrete reality of the world (Latour, 1987). In terms of learning, when an artefact becomes appropriated for a learning/teaching situation, it is necessary to divide into "didactic artefact" and "pedagogical artefact". The first one refers to all the disciplinary knowledge or professional behaviour needed to be learned to become an instrument. The second one refers to the appropriate representation of the scenario needed for its teaching (Marquet et Coulibaly, 2007).

However, the inclusion of technologies for learning, has created another obstruction on the development of trainings. This technology could interfere on the balance between the didactic and educational artefact, with the knowledge to be acquired, or the skill to be developed, associated with its teaching scenario, could be relevant with the potential inappropriate use of ICT (Marquet, 2012).

One example of instrumental conflict occurs when a technical system dedicated to a family of disciplinary objects is used inappropriately by the learner/user or teacher/trainer. In this type of situation, neither the learning contents, nor the functionalities of the system are involved. As an example, teachers can prevent students from accessing the properties of some specific subject manipulated objects that the software exploits, since these same properties are not highlighted when a figure could be done by hand (Denami \& Marquet, 2016). In this case, modeling the trainings for the majority of cases where this conflict is not expected to occur, an actual incoherence is shown (Mitgutsch \& Alvarado, 2012). 
This empirical model on the designing of digital trainings begins by identifying the elements to include on the training (artefacts) in terms of technology (display), pedagogical (game design) and didactical (game play). Once those elements are identified, the formulation of cognitive tasks and exercises takes place through the pedagogical dimension. Once the learner executes the tasks, an amount of data is generated, tracked by the algorithms from an artificial intelligence to be analyzed. The data obtained is divided into several lexical outputs in terms of recognition of semantic unities (xAPI performance).

In this case, modeling the trainings for the majority of cases where this conflict is not expected to occur, an actual incoherence is shown due to the fact that some designers are still not able to difference this aspect through their courses (Mitgutsch \& Alvarado, 2012). The collected data describe the performance and results of each action. Knobbout and Van der Stappen (2017) quote an architecture on the analysis of learnings performance by SURF (2016). The strategy on the evaluation of the data collected will be given by the dialogue between the instruments of measurement. Using these elements, a new data of the complexity of the task are released. Rossi (2014) explains that the complexity of the cognitive task could be measured by the alterations of the level of performance of the learner. Those changes show the variation on the cognitive process and introduce, basically, the level of acknowledge of each learner.

With the new analyzed data, we could provide a formative feedback to both participants of the process (Banihashem, S \& al., 2018). First, the trainer. The data provide the elements of improvement and advice about which artefacts and pedagogical tasks should be reconsidered to include or exclude from the training. Second, the learner, whom could identify through the data the cognitive aspects where they had more difficulties during the training to overcome with (Song, D, 2018).

\section{PERFORMANCE TRACKING AND METHODOLOGY}

My-Serious-Game has structured an R\&D team to develop the authoring tool. This tool has been conceived to optimize trainings using xAPI technology and artificial intelligence. This is the first digital tool applying A.I. technology to allow companies to create a wide variety of collaborative and interactive training courses.

The objective of this project is to stablish a generic method of digital learning conception. In order to accomplish it, we have organized it in several stages. First, we have done a benchmarking about all the digital trainings produced by our company since 2014. After, we have classified under the instrument conflict theory the artefacts (technology, pedagogical and didactical) of each one of the. With this classification we could identify the empirical own model of conception from My-Serious-Game.

On the third stage, we have overviewed the literature on the design methods of digital training. The result allowed us to create a comparative chart between our model and those already applied. This chart would provide us the information related to the main cognitive subjects to consider on the conception process of digital trainings.

Once we have stablished the cognitive subjects, we have applied a framework of predictive behavior on learners and teachers' performances. From the learners, we will consider the learning outcomes with the activities measured by our experimental tool and for the teachers, we will track the path behavior on the design of digital trainings. Our predictive behavior is based after the analysis of our predictive learning model with a Delta of measurement and behavior.

At the same time, we have analyzed the tracking tools and the dialogue to communicate that data. First, we have written the syntaxes for the tracking on the learner's activities (xAPI). Also, we have defined the vectors to include in our matrix algorithm of 4 dimensions to identify that behavior.

Related to trainers, they are guided while they host training sessions using our engine advice. The training content is broadcasted from the trainer's digital tool (iPad, tablet, laptop, etc.) proposing to learners a set of cognitive activities. From a pedagogical perspective, the collaborative dimension using technology it's an advantage (Lebrun, 2006). Our product gives to the trainers the control on learners' performances on real time. Data collection such time, interactivity, scores among others, provide the trainer valuable information to optimize the training. 


\section{DISCUSSION}

By the time this paper is released, our work relies on the validation of our expert-concept (V1) which means to validate the Delta set for the trainings. We consider our method a key tool on the prediction of learning analytics. Besides, it highlights how trainers could improve digital trainings through data collected from user's experiences. Our work seeks to conceive a learning/working environment where instrumental conflict doesn't take place, and, at the same time, it allows to optimize the results obtained.

This conception is stablished by first: conceiving the cognitive activities to develop through digital trainings under the instrumental conflict theory. Then, track them to analyze our predictions and finally, reformulate a new path proposing predictive learning models.

At this stage, we already have conceived the structure of our cognitive tasks, as well as the pedagogical path. This structure contains the Delta settings in both measurement tools and learning prediction model. We would like to describe if the use of the authoring tool using an A.I. contributes to optimize the digital trainings under the influence of instrumental conflict. Our main hypothesis is that the use of the authoring tool contributes to optimize the conception of digital trainings under the influence of instrumental conflict.

\section{REFERENCES}

All, A \& al, 2015. Assessing the effectiveness of digital game-based learning: Best practices. Computers and Education. Vl 92-93. Retrieved from: http://doi.org/10.1016/j.compedu.2015.10.007

Banihashem, S K et al, 2018. Learning Analytics: A Systematic Literature Review, Interdiscip J Virtual Learn Med Sci. Retrieved from: doi: 105812/ijvlms.63024

Baron, G.-L. 2011. «Learning design », Paris. Recherche et formation. 68, pp. 109-120.

Bennane, A. 2012. Systèmes adaptatifs et tutoring. Une étude de cas par l'application de l'apprentissage par renforcement. (Thèse Doctorat. Université Mohammed V - Rabat). Retrieved from: http://otrohati.imist.ma/handle/123456789/45770

Cleveland, M. Olimpo, J. \& DeChenne-Peters, S. 2018 Investigating the Relationship between instructors' use of Active-Learning Strategies and Students' Conceptual Understanding and Affective Changes in Introductory Biology: A comparison of Two Active-Learning Environments. MAST Institute and School of Biological Sciences, University of Northern Colorado, Greely DOI: 10.1187/cbe.16-06-0181 Retrieved from: https://www.ncbi.nlm.nih.gov/pubmed/28389428

Denami, M. \& Marquet, P. 2016. Un Serious Game pour la formation professionnelle : le cas des opérateurs en milieu aseptique, Éducation \& Formation, é-307.

Song, D. 2018. Learning Analytics as an Educational Research Approach. International Journal of Multiple Research Approaches. Vol 10. No \&, 102-111. Retrieved from: http://doi.org/10.29034/ijmra.v10n1a6

Henry, F. 2007. Pratique de design pédagogique et instrumentation du concepteur, in M. Baron éd. Environnements informatisés et ressources numériques pour l'apprentissage, Paris : Hermès-Lavoisier, pp. 229 - 254.

Knobbout, J \& Van Der Stappen, E. 2017. A first Step Towards Learning Analytics: Implementing an Experimental Learning Analytics Tool. $30^{\text {th }}$ Bled eConference: Digital Transformation. Slovenia.

Konstantin Mitgutsch \& Narda Alvarado. 2012. Purposeful by design? a serious game design assessment framework. In Proceedings of the International Conference on the Foundations of Digital Games (FDG '12). ACM, New York, NY, USA, 121-128. Retrieved from: http://hdl.handle.net/1721.1/100701

Latour, B. 1987. La science en action, Paris, La Découverte, 1989, p 450.

Lebrun, M. 2006. e-learning pour enseigner et apprendre. Allier pédagogique et technologique. Louvain-la-Neuve. Academia-Bruylant.

Leroi-Gourhan, A. 1967. Le geste et la parole. Retrieved from: https://www.persee.fr/doc/hom_04394216_1967_num_7_3_366914

Linard, M. 2002. Conception de dispositifs et changement de paradigme en formation. Paris. Éducation Permanente, 152 , pp. $143-155$.

Loh, C. 2013. Improving the Impact and Return of Investment of Game-Based Learning. Virtual and Personal

Marquet, P. 2005. Intérêt du concept de conflit instrumental pour la compréhension des usages des EIAH. EIAH 2005 (Environnements Informatiques pour l'Apprentissage Humain), May 2005, Montpellier, France. INRP, pp. 383-388, 2005. <hal-00340395>. Retrieved from: https://hal.archives-ouvertes.fr/hal-00340395/document 
Marquet, P \& Coulibaly, B. 2007. Le concept de conflit instrumental une hypothèse explicative des non-usages des TIC. Les dossiers de l'ingénierie éducative «TICE : l'usage en travaux3 (Hors-série), 61-69

Marquet, P. 2012. e-learning et conflit instrumental : entre didactique, pédagogie et technique, Recherche et formation, $68,31-46$.

Ministère du Travail Français. 2014. La formation de salariés : principes généraux. Formation professionnelle. Retrieved from : http://travail-emploi.gouv.fr/formation-professionnelle/entreprises-et-formation/article/la-formation-dessalaries-principes-generaux

Mirriahi \& al, 2016. Generating actionable predictive models of academic performance. Proceedings of the $6^{\text {th }}$ International Conference on Learning Analytics \& Knowledge. Retrieved from: https://dl.acm.org/citation.cfm?doid=2883851.2883870

Paquette, G. 2014. Technology-based instructional design: Evolution and major trends. In J.M. Spector, M.D. Merril, J. Elen and M.J. Bishop, eds, Handbook of research on educational communication technology. New York, NY: Springer. pp. $661-671$

Peraya, D. 2002. Le cyberespace : Un dispositif de communication et de formation médiatisé. In S. Alava, (ed.) Cyberespace et formation ouvertes. Vers une mutation des pratiques de formation ? Brussels : DeBoeck. pp. $17-44$.

Peraya, D. 2010. Apprendre avec les technologies. Chapitre 1 : Médias et technologies dans l'apprentissage : apports - conflits. Paris. Presses universitaires de France.

Prince, M. 2004. Does Active Learning Work? A review of the research. Retrieved from: http://www4.ncsu.edu/unity/lockers/users/f/felder/public/Papers/Prince_AL.pdf

Rossi, J.P. 2012. Les mécanismes de l'apprentissage-Modèle et applications. Bruxelles. De Boeck. pp 72.

SURF - Collaborative organisation for ICT in Dutch education and research. Repport on 2016. Quoted by Knobbout \& Van Der Stappen (2017). 